\title{
Uptake of BRCA1 rearrangement panel testing: In individuals previously tested for BRCA1/2 mutations
}

Kristen Mahoney Shannon, MS, CGC $C^{1}$, Alona Muzikansky, PhD' ${ }^{2}$, Gayun Chan-Smutko, MS, CGC $C^{1}$, Kristen Baker Niendorf, MS, CGC $C^{1}$, and Paula D. Ryan, $M D, P h D^{1}$

\begin{abstract}
Purpose: Individuals undergoing genetic testing for BRCA1/2 mutations are routinely counseled about the sensitivity and specificity of testing. In August 2002, testing for 5 large genomic rearrangements in the BRCA1 gene that would not have been detected with full gene sequence analysis became commercially available. We present our data on uptake of the BRCA1 rearrangement panel testing in our clinical cancer genetics program. Methods: Women who participated in our clinical genetic testing program and had previously received an uninformative negative or variant of uncertain significance result from $B R C A 1 / 2$ full gene sequencing were invited to consider BRCA1 rearrangement panel testing. Results: Overall, 18/72 individuals underwent BRCA1 rearrangement panel testing. No significant differences were found in the levels of BRCAPRO scores $(P=0.406)$, age at testing ( $P=0.986$ ), number of children ( $P=0.35$ ) or number of siblings ( $P=0.4$ ) between individuals who chose to pursue additional testing with the rearrangement panel and those who declined. Fisher's Exact Test analysis showed that there is a negative association between having breast or ovarian cancer and being inclined to undergo rearrangement panel testing $(P=0.013)$. Conclusion: Individuals who undergo genetic testing will not consistently pursue additional or enhanced genetic testing. Future research is needed to clearly elucidate the factors associated with uptake of additional genetic testing. Genet Med 2006:8(12):740-745.
\end{abstract}

Key Words: BRCA1/2 testing, genetic testing uptake, decliners of genetic testing, BRCA1 rearrangement panel

The availability of laboratory testing for $B R C A 1$ and $B R C A 2$ (BRCA1/2) mutations ${ }^{1,2}$ has offered families with hereditary breast and ovarian cancer (HBOC) various opportunities to determine their genetic risk. These families now may benefit from confirming that the family history of disease is, in fact, hereditary. Unaffected members in families with a known mutation have the opportunity to undergo genetic testing to clarify their own personal risks. However, the decision regarding whether or not to undergo genetic testing can be complicated and difficult.

Prior to the availability of $B R C A 1 / 2$ genetic testing, some studies reported an overwhelming interest (up to $95 \%$ ) in genetic testing for HBOC. ${ }^{3-8}$ However, once genetic testing became available, actual uptake of the BRCA1/2 genetic test was lower than anticipated with reports ranging from 43 to $96 \% .^{5,9-14}$ Differences in the study design of these cohorts make it difficult to directly compare these rates. More recently, Brooks et al. ${ }^{15}$ found that $50 \%$ of women (and only $11 \%$ of

\footnotetext{
From the ${ }^{1}$ Massachusetts General Hospital Cancer Center/Center for Cancer Risk Analysis, Boston, Massachusetts and ${ }^{2}$ Massachusetts General Hospital Biostatistics Center, Boston, Massachusetts.

KM Shannon, MS, CGC, Massachusetts General Hospital Cancer Center/Center for Cancer Risk Analysis, 55 Fruit St - YAW 9800, Boston, MA 02115.

Submitted for publication March 20, 2006.

Accepted for publication September 29, 2006.
}

DOI: 10.1097/01.gim.0000250202.06200.6d men) who are eligible for $B R C A 1 / 2$ genetic testing actually pursued it.

A search of the literature regarding genetic testing indicates that BRCA1/2 test decliners have been studied very little. The limited data on decliners are typically based on individuals that have been involved in research studies (usually family studies). ${ }^{16}$ Individual test decliners who have participated in research may be very different from those test decliners in a clinical setting. For example, individuals involved in early research into HBOC were often motivated by the 'common good' (i.e. gene discovery) and not the individual information that arose from clinical genetic testing. Those in a clinical setting are most often motivated by individual test results and the impact that it may have on his/her personal situation. In addition, the vast majority of studies regarding uptake of genetic testing have reported on individuals in families where there is a known mutation, ${ }^{16}$ which, too, is quite different than in a clinicbased practice. In families with a known mutation, the test results are clear (i.e. positive or negative for the mutation) and the clinical implications concrete. In most individuals in the clinic, there are more possibilities in terms of results (i.e. positive, true negative and indeterminate negative) and the interpretation of the indeterminate negative is not clear in most cases. In a more recent paper, Foster et al. ${ }^{17}$ reported that $11 \%$ of individuals considering $B R C A 1 / 2$ genetic testing with a $50 \%$ a priori risk of carrying a familial mutation declined the test. These decliners were significantly younger and had lower levels 
of cancer worry than test acceptors in this cohort. The test decliners reported barriers to testing that included apprehension about the result, difficulty in traveling to the clinic, and taking time away from work/family.

Since its commercial availability in October 1996, the vast majority of clinical $B R C A 1$ and $B R C A 2$ genetic testing in the US has been done via Myriad Genetics Laboratories under the tradename "BRACAnalysis." Through this testing, Myriad offered full gene sequencing of all coding exons of BRCA1 and $B R C A 2$. According to Myriad's test specifications, full sequence determination in both forward and reverse directions of approximately $5400 \mathrm{bp}$ of $B R C A 1$ and $10200 \mathrm{bp}$ of $B R C A 2$ was performed. Exons 1 and 4 of $B R C A 1$ and exon 1 of $B R C A 2$ were not analyzed because they were noncoding. The noncoding intronic regions of $B R C A 1$ and $B R C A 2$ that were analyzed did not extend more than 20 base pairs proximal to the $5^{\prime}$ end and 10 base pairs distal to the $3^{\prime}$ end of each exon. At the time, Myriad quoted, "This assay will not detect deletion of complete exons or genes, or errors in RNA transcript processing unrelated to DNA exon sequence. The proportion of clinically significant defects in BRCA1 and BRCA2 attributable to such abnormalities is unknown but may be between 5 and 15\%." In August 2002, Myriad added enhanced testing for five BRCA1 large genomic rearrangements ${ }^{18-21}$ to the BRACAnalysis test. Early studies indicated that this further analysis detects an additional 2 to $3 \%$ of alterations. ${ }^{22}$ At that time, some genetic counseling programs in the US notified their BRCA1/2 clinical testing patients that had undergone BRACAnalysis testing prior to August 2002 that the sensitivity of the BRCA1/2 genetic test had changed, and offered the patients the option of additional testing.

This provided a unique opportunity to examine an entirely different cohort of individuals for uptake rates of genetic testing. These were individuals who had previously pursued $B R C A 1 / 2$ genetic testing (i.e. were test acceptors) and were now able to consider genetic testing again. Based on our review of the literature, this type of cohort has never been described in the literature. One manuscript by authors at $\mathrm{Myriad}^{23} \mathrm{de}-$ scribes the clinical characteristics of individuals with germline mutations in BRCA1/2. The data gleaned from this report suggests that $11.3 \%(322 / 2861)$ of individuals pursued additional testing once they received a negative test result from a panel of three specific founder mutations (Ashkenazi). However, the overall cohort was not described and the clinical reasons for uptake of the additional test were not clarified. Here we present our descriptive data on uptake of the BRCA1 rearrangement panel testing at our clinical cancer genetics program.

\section{MATERIALS AND METHODS}

\section{Study design and sample}

We used a retrospective cohort study design involving women who had previously undergone $B R C A 1 / 2$ genetic testing at our center prior to August 2002. An overall schema of the study design is presented in Figure 1.

In March 2003, 72 letters were mailed to women who had participated in our clinical genetic testing program and had previously received an uninformative negative (UN) (i.e. a negative test result when no mutation is known in the family) $(\mathrm{N}=62)$ or variant of uncertain significance (VUS) result $(\mathrm{N}=10)$ from $B R C A 1 / 2$ full gene sequencing. The letter sent to this group indicated that current data suggest that full gene sequencing may miss up to $15 \%{ }^{22,24}$ of alterations in BRCA1 and $B R C A 2$, and that further analysis was now available to detect some additional types of alterations. The letter also explained that early studies have indicated that this further analysis detects an additional 2 to $3 \%$ of alterations in the BRCA1 gene. The cost of this further analysis (\$325) was provided in the letter as well as information that in some cases this may be reimbursable by insurance. Finally, the letter indicated that this testing was not appropriate for all families, but encouraged the patient to call for further information. By January 1, 2004, only 6/72 women had pursued BRCA1 rearrangement testing

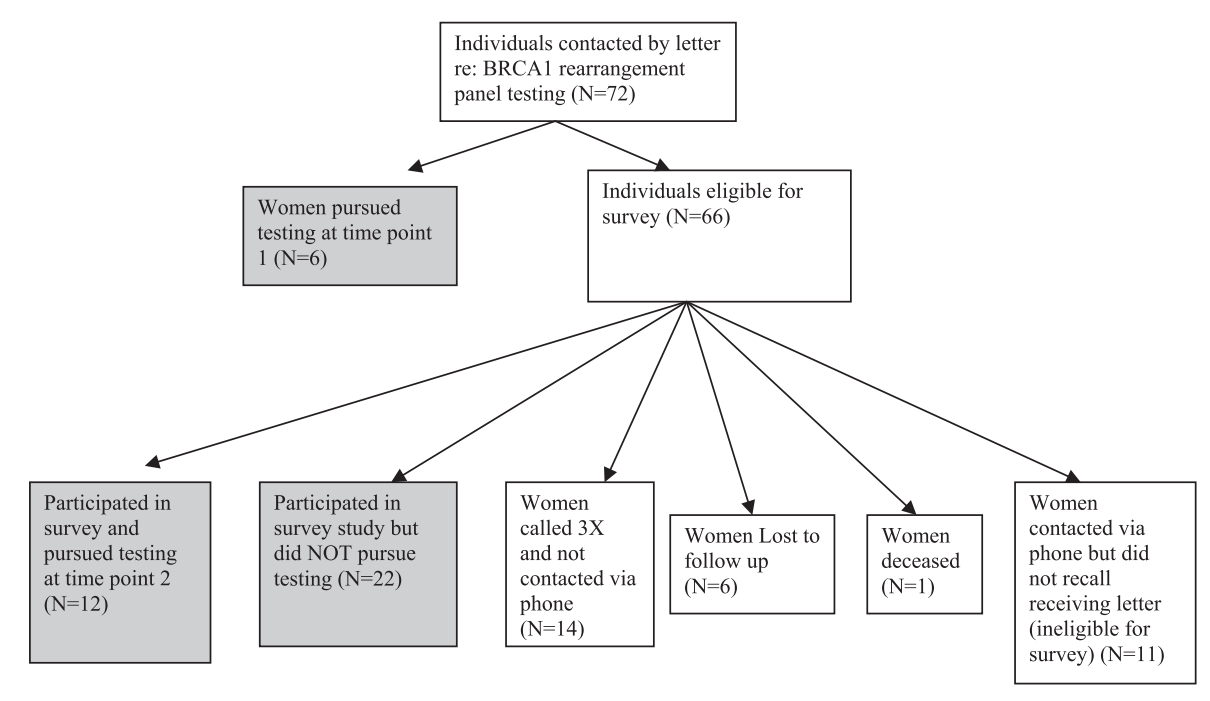

Fig. 1. Study schema. 
after receiving the letter, leaving 66 remaining women eligible for the current study.

\section{Data collection}

The institutional review board at Partners' HealthCare approved this study before implementation. Beginning in January 2004, eligible participants were contacted by the genetic counselor that had been involved in their original testing via phone and invited to participate in a phone survey that sought to identify factors that influenced a person's decision about whether or not to have additional genetic testing. Contact was attempted at least three times for each potential participant over the course of 6 months. Each potential participant was advised that her individual responses would not be shared with her healthcare providers or become part of her medical records, and that her identifiable information would not be shared with clinicians or researchers outside of the study. Each woman was also advised that participation was voluntary and that she could feel free to decline answering any questions that she did not want to answer. Verbal consent was obtained prior to initiation of the phone survey. Women that were contacted via phone that did not recall receiving the initial letter (sent in March 2003) were not eligible for the study. In these instances, the letter was re-sent and the individual was encouraged to call with questions.

\section{Survey}

The phone-administered survey consisted of three individual questions, one of which had additional questions if the answer was in the affirmative. Each participant was asked if she had discussed the letter and/or the testing described with any of her healthcare professionals. If the participant answered in the affirmative, she was asked what type of professional (e.g. PCP, surgeon, medical oncologist, etc.) was involved, at what time interval the discussion took place and whether or not a suggestion/recommendation was made by the health care professional. The next question asked each participant if she had had this additional testing done. Finally, each participant was asked the open-ended question, "Why haven't you pursued testing?" The genetic counselor performing the interview then coded these responses where more than one response was possible. The responses to this question can be found in the first column of Table 1.

Once the phone survey was complete, the participant was asked if she had any other questions and the interview was terminated. The genetic counselor then noted whether or not the participant had (voluntarily) asked for additional information about testing and/or scheduled an appointment for the additional testing. Data regarding actual uptake of testing was obtained from the medical record review in September 2004.

\section{Statistical methods}

All data were initially entered into a spreadsheet created on Microsoft Excel (2000). Demographic data on all subjects was obtained from medical records and entered into the investigator database. BRCAPRO scores, which represent the probability that the participant carries a mutation in $B R C A 1$ or $B R C A 2$, were
Table 1

Participants' responses to survey question, "Why haven't you pursued the rearrangement test?"

\begin{tabular}{|c|c|c|c|}
\hline \multirow[b]{2}{*}{ Response } & \multicolumn{3}{|c|}{ No. of times response reported } \\
\hline & $\begin{array}{l}\text { Overall } \\
\text { cohort }\end{array}$ & $\begin{array}{l}\text { Not pursued } \\
\text { test }\end{array}$ & $\begin{array}{c}\text { Pursued } \\
\text { test }\end{array}$ \\
\hline $\begin{array}{l}\text { I was going to call, but you } \\
\text { called first }\end{array}$ & 1 & 1 & 0 \\
\hline $\begin{array}{l}\text { I'm too busy, don't have } \\
\text { time - will do in the } \\
\text { future }\end{array}$ & 8 & 2 & 6 \\
\hline Confidentiality concerns & 0 & 0 & 0 \\
\hline $\begin{array}{l}\text { Didn't understand the } \\
\text { letter/letter was } \\
\text { confusing }\end{array}$ & 3 & 1 & 2 \\
\hline $\begin{array}{l}\text { Didn't think the test } \\
\text { applied to me/my family } \\
\text { (i.e. The test isn't } \\
\text { appropriate for me/my } \\
\text { family) }\end{array}$ & 5 & 2 & 3 \\
\hline $\begin{array}{l}\text { Didn't think the additional } \\
\text { test increased the } \\
\text { sensitivity of testing } \\
\text { enough }\end{array}$ & 7 & 7 & 0 \\
\hline $\begin{array}{l}\text { My healthcare } \\
\text { professional(s) didn't } \\
\text { think I should }\end{array}$ & 3 & 3 & 0 \\
\hline $\begin{array}{l}\text { Just too much of a bother } \\
\text { to have it redone }\end{array}$ & 2 & 1 & 1 \\
\hline $\begin{array}{l}\text { Just not interested in } \\
\text { genetic testing anymore }\end{array}$ & 11 & 10 & 1 \\
\hline I just don't want to know & 1 & 1 & 0 \\
\hline Other & 7 & 4 & 3 \\
\hline
\end{tabular}

calculated using CaGene 3.3.1 for each participant. For the purposes of this study, both invasive breast cancer (IBC) as well as ductal carcinoma in situ (DCIS) was considered breast cancer.

To assess differences between patients electing to pursue genetic testing (at any time point) and decliners, Fisher exact test was performed on all $2 \times 2$ tables. The Cochran-Armitage Trend Test (for $2 \times \mathrm{n}$ table) was employed to determine association with the number of siblings and children. $T$-test was used to assess the difference in means of all other continuous variables. Likelihood ratio test was performed to assess whether the number of those pursuing the test after receiving a letter is significantly different than the number of those pursuing the test after the telephone call. The test statistic was compared against a $\chi^{2}$ distribution with one degree of freedom. Ninety percent exact binomial CI was provided for the rates of participants pursuing a test at any timepoint.

\section{RESULTS}

\section{Characteristics of cohort}

We present the data here from all women with whom contact was made at any point in the study (i.e. those subsets 
Table 2

Participant demographics

\begin{tabular}{lccc}
\hline & $\begin{array}{c}\text { Women that } \\
\text { pursued } \\
\text { rearrangement } \\
\text { testing }(\mathrm{N}=18)\end{array}$ & $\begin{array}{c}\text { Women did not } \\
\text { pursue } \\
\text { rearrangement } \\
\text { testing }(\mathrm{N}=22)\end{array}$ & $\begin{array}{c}\text { Overall } \\
\text { cohort } \\
(\mathrm{N}=40)\end{array}$ \\
$\begin{array}{l}\text { Descriptor } \\
\begin{array}{c}\text { Breast or ovarian } \\
\text { cancer diagnosis }\end{array}\end{array}$ & 13 & 22 & 35 \\
$\begin{array}{c}\text { Breast cancer } \\
\text { diagnosis }\end{array}$ & 12 & 18 & 30 \\
$\begin{array}{c}\text { Ovarian cancer } \\
\text { diagnosis }\end{array}$ & 1 & 4 & 5 \\
$\begin{array}{c}\text { Mean age at cancer } \\
\text { diagnosis }\end{array}$ & 44.2 & 47.1 & 46 \\
$\begin{array}{c}\text { Mean age at initial } \\
\text { BRCA1/2 testing }\end{array}$ & 48.3 & 51.2 & 50 \\
$\begin{array}{l}\text { Mean BRCAPRO score } \\
\text { Median no. of children }\end{array}$ & 16.8 & 9.7 & 12.9 \\
Median no. of siblings & 2 & 2 & 2 \\
\hline
\end{tabular}

shaded in Fig. 1) $(\mathrm{N}=40)$. The demographics of the entire cohort are presented in Table 2.

The vast majority ( $88 \%$ ) of women had a previous diagnosis of breast or ovarian cancer. All women were Caucasian and only one $(2.5 \%)$ woman was of Ashkenazi Jewish ancestry. The mean age at cancer diagnosis for those women who had a diagnosis of cancer was 46 years (range 21-68) and the mean age at initial $B R C A 1 / 2$ sequencing was 50 (range $31-70$ ). The mean BRCAPRO score for the cohort was $12.9 \%$ (range 0.4-65.3). The median number of children was 2 (range $0-6$ ) with $8.33 \%$ of participants having more than 3 children. Median number of siblings was 2 (range $0-9$ ) with $29.27 \%$ having more than 3 siblings.

Of the 34 survey participants, 8 (23.5\%) individuals reported having discussed the letter and/or the rearrangement testing with a healthcare provider. The most common provider mentioned was a medical oncologist $(\mathrm{N}=6)$, followed by primary care physician $(\mathrm{N}=3)$, radiation oncologist $(\mathrm{N}=1)$ and surgeon $(\mathrm{N}=1)$. When asked about the outcome of the discussion with the provider, 2 individuals indicated that the provider suggested they pursue the test, 3 individuals indicated that the provider suggested they not pursue the test and 3 individuals indicated there was no suggestion at all from the healthcare provider. None of the survey participants had undergone the rearrangement testing outside of our program.

Survey participants' responses to the open-ended question, "Why did you not pursue the test" are shown in Table 1. The most commonly reported answer was "Just not interested in genetic testing anymore" and the second most common answer was "I'm too busy - will do in the future".

Responses classified as "other" included one individual who responded that she did not pursue testing because she was having difficulty getting things 'worked out' in regards to billing for the initial test. She enlisted the counselor's help and the billing issues were worked out. This participant eventually un- derwent BRCA1 panel testing. This was the only participant in our sample to reference cost/insurance coverage as an issue for not pursuing the test. Also classified as "other" included one woman who felt that testing was just too difficult emotionally to reconsider, one woman who didn't reconsider it because she had received a VUS result and didn't think additional testing would help, two women who were too overwhelmed with other family issues to consider this, and two women who 'just didn't take it seriously'.

\section{Participants that underwent rearrangement testing}

Table 2 shows the demographics of those participants that did pursue versus those that did not pursue BRCA1 rearrangement testing. No significant differences were found in the levels of BRCAPRO scores $(P=0.406)$, age at testing $(P=0.986)$, number of children $(P=0.35)$ or number of siblings $(P=0.4)$ between test takers and decliners. Fisher's Exact Test analysis showed that there is a negative association between having breast or ovarian cancer and being inclined to undergo rearrangement panel testing $(P=0.013)$.

Of the survey participants that had discussed the testing with their healthcare provider $(\mathrm{N}=8), 4(50 \%)$ decided to pursue rearrangement testing after the survey was completed. Of these four, two indicated that their provider had suggested they pursue the test and two indicated that there was no suggestion from their healthcare provider.

During the phone interview, each participant was asked the open-ended question, "Why did you not pursue the test" (after receiving the initial letter in March 2002). The responses to this question are shown in Table 1 and are stratified by those that eventually underwent the additional testing and those that continued to decline the additional testing. The most common answer to this question for those who eventually took the test was "I'm too busy - will do in the future while the most common answer for those who did not undergo additional testing was, "Just not interested in genetic testing anymore".

The number of individuals taking the test prior to the phone call survey, after the phone call survey and none at all is presented in Figure 2. This distribution was compared against a null of equal number of test takers prior to and after the survey. The $P$-value for this test was 0.15 , suggesting no significant difference between the number of test takers before and after
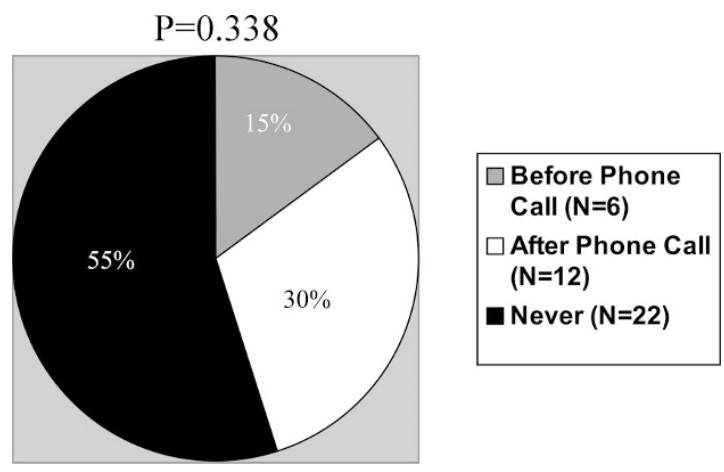

Fig. 2. Timepoint of rearrangement panel testing. 
the survey. The $90 \% \mathrm{CI}$ for the proportion (in brackets) of test pursuers before the survey $(6 / 40)$, after the survey $(12 / 34)$ or at any time point $(18 / 40)$ are $(0.067,0.274),(0.217,0.508)$ and $(0.314,0.591)$ respectively.

\section{DISCUSSION}

Our study adds to the limited body of literature regarding individuals that decline genetic testing. In this clinic-based cohort $45 \%$ of individuals pursued additional testing for $B R C A 1$ rearrangements after having received an uninformative test result on $B R C A 1 / 2$ gene sequencing. This is, to our knowledge, the first descriptive report of a a cohort of individuals who had undergone prior genetic testing, so it is difficult to compare this percentage to other reports of uptake of BRCA testing.5,9-14 The uptake rate is very similar to the study of Brooks et al., ${ }^{15}$ who found that $50 \%$ of women in their clinic based sample pursued BRCA genetic testing. It is also substantially higher than the $12.6 \%$ of Ashkenazi individuals that had gone on for full gene sequencing after a negative 3 site test. ${ }^{23}$

An interesting point from our study was that many of those individuals who declined the enhanced test even after the phone intervention cited that they just did not want to go through the testing process again. It is possible that these women found relief enough in their original test and were no longer anxious about genetic susceptibility. This would be consistent with Phillips et al..$^{25}$ finding that one of the most important factors that influence the decision to undergo testing is the potential for relief if not found to be a carrier.

It is noteworthy that, although not reaching significance, a larger number of individuals $(\mathrm{N}=12)$ pursued the rearrangement test after the phone intervention than with just the letter alone $(\mathrm{N}=6)$. From this data, it is difficult to discern why. However, it is plausible that the letter method for notifying patients was simply disregarded (11 individuals contacted via phone reported that they didn't even remember receiving the letter). It would be important, therefore, to note the importance of verbal communication (e.g. phone follow up) with this type of information.

Our study has limitations that are worth noting. First, the small sample size may limit the ability to generalize. In addition, it is possible that the data may be biased in that only individuals who were reached for comment on the enhanced testing were included. It is conceivable that those individuals who did not return our phone call were clearly not interested in genetic testing any more. This would have significantly lowered the percentage of individuals pursuing the test.

Our study has implications for the future of genetic testing and genetic counseling. Recently, it has been reported that a proportion of $B R C A 1 / 2$ mutations are missed using the current genetic testing methodology. ${ }^{26}$ In addition, it is likely that more genes that contribute to HBOC will be discovered in the future. Therefore, it will be important for clinicians to re-approach their patients, explain the new information, and offer them additional testing as appropriate. Our data support the idea that mailing literature may not be the most effective way of getting information to patients. It may be more appropriate to contact these patients by phone (or in person) so that the message is clear and the patient has the ability to ask questions. It may also be appropriate to send information about additional testing to the original referring physician so that they can discuss it with their patient.

Our data also suggest that once individuals undergo genetic testing, they are not consistently going to pursue additional testing. Some of the individuals in this subset cited that the anxiety and worry associated with the genetic testing process was something that they did not want to go through again. This has tremendous implications for the future of genetic testing and genetic research. If individuals are unwilling to undergo enhanced or additional genetic testing, it will undoubtedly leave families with $\mathrm{HBOC}$ without the ability to perform informative carrier testing when this could be a reality. The unaffected members of the family therefore will have to be cared for as if they were at increased risk of cancer - which carries both emotional implications for the individual as well as financial implications for the health care system.

In conclusion, individuals who undergo genetic testing will not all consistently pursue additional or enhanced genetic testing. A phone call to discuss the details associated with enhanced testing may have a slight impact on the uptake of testing, as compared to simply sending a letter describing the additional testing. Future research is needed to clearly elucidate the factors associated with uptake of additional genetic testing.

\section{ACKNOWLEDGMENTS}

We would like to thank all the women who participated in this study.

\section{References}

1. Miki Y, Swensen J, Shattuck-Eidens D, Futreal PA, et al. A Strong candidate for the breast and ovarian cancer susceptibility gene BRCA1. Science 1994;266:66-71.

2. Wooster R, Bignell G, Lancaster J, Swift S, et al. Identification of the breast cancer susceptibility gene BRCA2. Nature 1995;378:789-792.

3. Lerman C, Daly M, Masny A, Balshem A. Attitudes about genetic testing for breastovarian cancer susceptibility. J Clin Oncol 1994;12:843-850.

4. Lerman C, Seay J, Balshem A, Audrain J. Interest in genetic testing among firstdegree relatives of breast cancer patients. Am J Med Genet 1995;57:385-392.

5. Lerman C, Narod S, Schulman K, Hughes C, et al. BRCA1 testing in families with hereditary breast-ovarian cancer. A prospective study of patient decision-making and outcomes. JAMA 1996;275:1885-1892.

6. Press NA, Yasui Y, Reynolds S, Durfy SJ, et al. Women's interest in genetic testing for breast cancer susceptibility may be based on unrealistic expectations. Am J Med Genet 2001;99:99-110.

7. Chaliki H, Loader S, Levenkron JC, Logan-Young W, et al. Women's receptivity to testing for a genetic susceptibility to breast cancer. Am J Public Health 1995;85:11331135 .

8. Struewing JP, Lerman C, Kase RG, Giambarresi TR, et al. Anticipated uptake and impact of genetic testing in hereditary breast and ovarian cancer families. Cancer Epidemiol Biomarkers Prev 1995;4:169-73.

9. Beisecker BB, Ishibe N, Hadley DW, Giambarresi TR, et al. Psychosocial factors predicting BRCA1/BRCA2 testing decisions in members of hereditary breast and ovarian cancer families. Am J Med Genet 2000;93:257-263.

10. Julian-Reynier C, Sobol H, Sevilla C, Nogues C, et al. Uptake of hereditary breast/ ovarian cancer genetic testing in a French national sample of BRCA1 families. The French Cancer Genetic Network. Psychooncology 2000;9:504-510.

11. Patenaude AF. Acceptance of invitation for p53 and BRCA1 predisposition testing. Psychooncology 1996;5:241-250. 
12. Reichelt JG, Dahl AA, Heimdal K, Moller P. Uptake of genetic testing and pre-test levels of mental distress in Norwegian families with known BRCA1 mutations. Dis Markers 1999;15:139-143.

13. Meijers-Heijboer EJ, Verhoog LC, Brekelmans CTM, Seynaeve C, et al. JGM. Presymptomatic DNA testing and prophylactic surgery in families with a BRCAl or BRCA2 mutation. Lancet 2000;355:2015-2020.

14. Clark S, Bluman LG, Borstelmann N, Regan K, et al. Patient motivation, satisfaction and coping in genetic counseling and testing for BRCA1 and BRCA2.J Genet Coun 2000;9:219-235.

15. Brooks L, Lennard F, Shenton A, Lalloo F, et al. BRCA1/2 predictive testing: A study of uptake in two centers. Eur J Hum Genet 2004;12(8):654-62.

16. Lerman C, Hughes C, Lemon SJ, Main D, et al. What you don't know can hurt you: adverse psychologic effects in members of BRCA1-linked and BRCA2-linked families who decline genetic testing. J Clin Oncol 1998;16:1650-1654.

17. Foster C, Evans DGR, Eeles R, Eccles D, et al. Non-Uptake of predictive genetic testing for BRCA1/2 among relatives of known carriers: attributes, cancer worry, and barriers to testing in a multicenter clinical cohort. Genetic Testing 2004;8: 23-29.

18. Petrij-Bosch A, Peelen T, van Vliet M, van Eijk R, et al. BRCA1 genomic deletions are major founder mutations in Dutch breast cancer patients. Nat Genet 1997;17: 341-345.

19. The BRCA1 Exon 13 Duplication Screening Group. The exon 13 duplication in the BRCA1 gene is a founder mutation present in geographically diverse populations. Am J Hum Genet 2000; 67 (1):207-212.
20. Rohlfs EM, Puget N, Graham ML, Weber BL, et al. An Alu-mediated $7.1 \mathrm{~kb}$ deletion of BRCA1 exons 8 and 9 in breast and ovarian cancer families that results in alternative splicing of exon 10. Genes Chromosomes Cancer 2000;28: 300-307.

21. Ward BD, Hendrickson BC, Judkins T, Deffenbaugh AM, et al. A multi-exonic BRCA1 deletion identified in multiple families through single nucleotide polymorphism haplotype pair analysis and gene amplification with widely dispersed primer sets. J Mol Diagn 2005;7:139-142.

22. Unger MA, Nathanson KL, Calzone K, Antin-Ozerkis D, et al. Screening for genomic rearrangements in families with breast and ovarian cancer identifies BRCA1 mutations previously missed by conformation-sensitive gel electrophoresis or sequencing. Am J Hum Genet 2000;67:841-850.

23. Frank TS, Deffenbaugh AM, Reid JE, Hulick M, et al. Clinical characteristics of Individuals with germline mutations in BRCA1 and BRCA2: Analysis of 10,000 individuals. J Clin Oncol 2002;20:1480-1490.

24. Ford D, Easton DF, Stratton M, Nard S, et al. Genetic heterogeneity and penetrance analysis of the BRCA1 and BRCA2 genes in breast cancer families. Am J Hum Genet 1998;62:676-689.

25. Phillips KA, Warner E, Meschino WS, Hunter J, et al. Perceptions of Ashkenazi Jewish breast cancer patients on genetic testing for mutations in BRCAl and BRCA2. Clin Genet 2000;57:376-387.

26. Walsh T, Casadei S, Coats KH, Swisher E, et al. Spectrum of mutations in BRCA1, BRCA2, CHEK2, and TP53 in families at high risk of breast cancer. JAMA 2006;295: 1379-1388. 